\title{
Analisis Kelayakan dan Faktor Usahatani Janggelan di Kawasan Hutan Pinus
}

\author{
Susantriana Dewi ${ }^{1}$, Mila Diana Sari ${ }^{2}$ \\ ${ }^{1}$ Fakultas Ekonomi, Universitas Merdeka Ponorogo, Jl. Pacar 30, Ponorogo, 63418 \\ E-mail: susanardino@gmail.com \\ ${ }^{2}$ Fakultas Ekonomi, Universitas Merdeka Ponorogo, Jl. Pacar 30, Ponorogo, 63418 \\ E-mail: miladianasari.se@gmail.com
}

\begin{abstract}
Janggelan farming is mostly carried out under pine stands, but the feasibility of this farming has never been done, besides that, the production factors that affect farming are also unknown, so it needs research that can be used as a basis to determine the steps to be taken in farming to increase the income of janggelan farmers so that worthy of being occupied by the community around the pine forest. The purpose of this study was to determine the feasibility and production factors that affect janggelan farming in the pine forest area. The method used in this research is a survey method to collect primary data and secondary data. Data were analyzed using the $F$ test and t test. Based on the research results, it was found that the cultivation of janggelan under pine stands was feasible. The biggest factor affecting the production of janggelan is the use of manure.
\end{abstract}

Keywords—: Feasibility; farming; janggelan; pine forest.

\section{PENDAHULUAN}

Masyarakat sekitar hutan banyak memanfaatka hutan untuk memenuhi kebutuhan hidup. Salah satu cara yang ditempuh adalah budidaya tanaman dibawah tegakan tanaman hutan dengan sistem tumpangsari. Dibawah tegakan tanaman pinus dapat digunakan untuk membudidayakan tanaman janggelan karena tanaman pinus memiliki jarak tanaman yang lebar (2 x 3 m). Janggelan di Ponorogo banyak terdapa tipe yaitu batang hijau dan ungu (Yazid et al., 2016). Sebagai mata pencaharian masyarakat disekitar hutan maka tanaman janggelan (tanaman tumpangsari) mempunyai peranan dalam meningkatkan pendapat masyarakat. Tanaman tumpangsari merupakan langkah yang tepat untuk meningkatkan pendapatan masyarakat sekitar hutan di Kabupaten Ponorogo (Ansori, 2018)

Pendapatan masyarakat akibat budidaya janggelan dikawasan hutan pinus bervariasi tergantung pada jumlah biaya dan hasil janggelan yang dipanen serta harga janggelan dipasaran (Theresia et al, 2016). Masyarakat sekitar hutan tidak mengetahu apakah usaha yang ditekuni selama ini layak atau tidak dilakukan dan faktor produksi apa yang perlu dilakukan inovasi sehingga usahatani ini dapat dikembangkan menjadi lebih baik dalam menopang pendapat keluarga (Rahayu et al., 20160. Oleh sebab itu dalam penelitian ini bertujuan untuk menentukan kelayakan usahatani janggelan dan mencari faktor produksi yang mempengaruhi usahatanai janggelan.

Penelitian ini penting untuk dilaksanakan karena dapat dimanfaatkan sebagai ukuran layak tidaknya usahatani janggelan dilakukan di areal hutan pinus dan faktor produksi apa yang perlu dilakukan inovasi sehingga usahatani janggelan merupakan usahatani yang dapat meningkatkan pendapatan masyarakat sekitar hutan pinus.

Pustaka yang dirujuk hanya yang benar-benar penting dan relevan dengan permasalahan. Pustaka dalam teks minimal 12 referensi. Diharapkan 50\% dari referensi merupakan referensi tahun (2015-2017). Setiap mengambil data atau mengutip pernyataan dari pustaka lain, penulis wajib menuliskan sumber rujukannya. Rujukan atau sitasi ditulis di dalam uraian/teks dengan cara nama penulis dan tahun (Irwan dan Salim, 1998). Jika penulis lebih dari dua, maka hanya dituliskan nama penulis pertama diikuti "dkk" atau "et al." (Bezuidenhout dkk., 2009; Roeva, 2012). Semua yang dirujuk di dalam teks harus didaftarkan di bagian Daftar Pustaka, demikian juga sebaliknya, semua yang dituliskan di Daftar Pustaka harus dirujuk di dalam teks. Jumlah halaman maksimal 7 halaman, di luar referensi.

\section{METODE PENELITIAN}

Penelitian ini dilakukan dengan 3 tahapan yaitu penentuan data sekunder, survey pada petani dan penentuan kelayakan usahatani tanaman janggelan. Data sekunder diperoleh untuk mendapatkan gambaran keadaan masyarakat. Survey petani dilakukan untuk mendapatkan data riil mengenai factor produksi yang berpengaruh terhadap usahatani janggelan. Adapun analisis kelayakan usahatani diperoleh dengan menggunakan kriteria R/C rasio yang dikemukan oleh Luntungan (2012).

Penelitian akan dilaksanakan di kecamatan Ngrayun Kabupatan Ponorogo yang merupan sentral janggelan di kabupaten Ponorogo. Metode penelitian ini menggunakan metode survey lapang untuk mendapatkan data sekunder dan data primer. Data sekunder meliputi keadaan masyarakat sekitar hutan yang membudidadayakan janggelan di kawasan hutan pinus. Data primer 
Website : http://agritek.unmermadiun.ac.id/index.php/agritek

didapatkan dengan metode survey untuk menentukan faktor produksi yang mempengaruhi usahata tani janggelan melalui pengisian kuisioner. Pada lembar kuisioner memliputi data petani, luas tanam, penggunaan pupuk (organik, anorganik), jarak lahan, intensitas naungan, biaya penggarapan, biaya angkuatan, biaya panen, hasil panen dan harga hasil panen.

Analisis pendapatan dilakukan dengan menggunkan metode Fadli ( 2014).

$$
P=T R-T C
$$

$$
\mathrm{P}=\text { pendapatan }
$$

$\mathrm{TR}=$ Total Revenue (total penerimaan)

$\mathrm{TC}=$ Total Cost $($ totalbiaya $)$

$\mathrm{JP}=$ jumlah produksi

$$
T R=J P \bullet H P
$$

$\mathrm{HP}=$ harga produksi

$$
T C=B T+B V
$$

BT = biaya tetap

$\mathrm{BV}$ = biaya variable

Analisis kelayakan usaha dilakukan dengan menggunakan metode $\mathrm{R} / \mathrm{C}$ rasio.

$$
R / C=T R / T C
$$

Dimana :

$\mathrm{R} / \mathrm{C}>1$ : usaha tani janggelan layak diusahakan

$\mathrm{R} / \mathrm{C}<1$ :usaha tani janggelan tidak layak diuasahakan

$\mathrm{R} / \mathrm{C}=1$ :usaha tani janggelan tidak layak diusahakan

Analisis factor produksi yang mempengaruhi usaha tani janggelan dilakukan dengan menggunakan fungsi Cobb Douglas

$$
Y=a X 1^{b 1} \bullet X 2^{b 2} \bullet X 3^{b 3} \bullet X 4^{b 4} \bullet X 5^{b 5} \bullet X 6^{b 6} \bullet X 7^{b 7} \bullet X 8^{b 8} \bullet X 9^{b 9} \bullet X 10^{b 10} \bullet e(5)
$$

Persamaaninidapatditransformasikandalambentukpersamaan linier berikut :

$$
\begin{aligned}
\operatorname{Ln} Y= & \operatorname{Ln} a+b 2 \operatorname{Ln} X 2+b 3 \operatorname{Ln} X 3+b 4 \operatorname{Ln} X 4+b 5 \operatorname{Ln} X 5+ \\
& b 6 \operatorname{Ln} X 6+b 7 \operatorname{Ln} X 7+b 8 \operatorname{Ln} X 8+b 9 \operatorname{Ln} X 9+ \\
& b 10 \operatorname{Ln} X 10+\text { Lne }
\end{aligned}
$$

Dimana :

$$
\begin{aligned}
& \mathrm{Y}=\text { hasil } \\
& \mathrm{X} 1=\text { luaslahan } \\
& \mathrm{X} 2=\text { pupuk urea } \\
& \mathrm{X} 3=\text { pupukPonska } \\
& \mathrm{X} 4=\text { pupukkandang } \\
& \mathrm{X} 5=\text { jaraklahankerumah } \\
& \mathrm{X} 6=\text { jarak tanam } \\
& \mathrm{X} 7=\text { biayatanam } \\
& \mathrm{X} 8=\text { biayaPerawatan } \\
& \mathrm{X} 9=\text { biayapanen } \\
& \mathrm{X} 10=\text { biayatransportasi }
\end{aligned}
$$

Uji statistik menggunakan uji $\mathrm{F}$ untuk menentukan pengaruh factor produksi secara komulatif terhadap pendapatan petani dan Uji t untuk menentukan pengaruh masing masing factor terhadap pendapatan petani.

\section{III.HASIL DAN PEMBAHASAN}

Kecamatan Ngrayun merupakan salah satu kecamatan di Kabupaten Ponorogo, dengan letak astronomis $111^{\circ} 17^{\prime}-111^{\circ} 52^{\prime}$ bujur timur dan $7^{\circ} 49^{\prime}-8^{\circ} 20^{\prime}$ Lintang selatan dengan ketinggian 92 - $2563 \mathrm{~m}$ dpl. Penghasilan utama di kecamatan Ngrayun adalah sektor pertanian yaitu 91,9 persen, kemudian diikuti oleh sektor perdagangan sebesar 3,2 persen (Tabel 1)

Tabel 1. Jenis penghasilan

\begin{tabular}{rlrr}
\multicolumn{4}{c}{ Tabel 1. Jenis penghasilan } \\
\hline No & $\begin{array}{l}\text { Jenis } \\
\text { penghasilan }\end{array}$ & $\begin{array}{l}\text { Jumlah } \\
\text { Penduduk }\end{array}$ & \multicolumn{2}{c}{ Persentase } \\
\hline 1 & Pertanian & 34507 & 91,9 \\
2 & Pertambangan & 48 & 0,1 \\
3 & Industri & 332 & 0,9
\end{tabular}

Volume 21 Nomor 2 September 2020, AGRI-TEK | 64 
Website : http://agritek.unmermadiun.ac.id/index.php/agritek

\begin{tabular}{llrr}
4 & Kontruksi & 376 & 1,0 \\
5 & Perdagangan & 1198 & 3,2 \\
6 & Jasa & 463 & 1,2 \\
7 & Transportasi & 637 & 1,7 \\
\hline & & 37561 & 100 \\
\hline
\end{tabular}

Petani yang bergerak dalam tanaman janggelan adalah petani yang didominasi oleh petani tua yaitu yang berumur diatas 50 tahun, dengan jumlah 64 persen dari total petani (Gambar 1). Sedangkan apabila dilihat dari tingkat pendidikan maka didapakan bahwa tingkat pendidikan petani janggelan terbesar pada pendidikan SMP yaitu sebesar 33 persen, kemudian diikuti oleh SD sebesar 32 persen (Gambar 2).

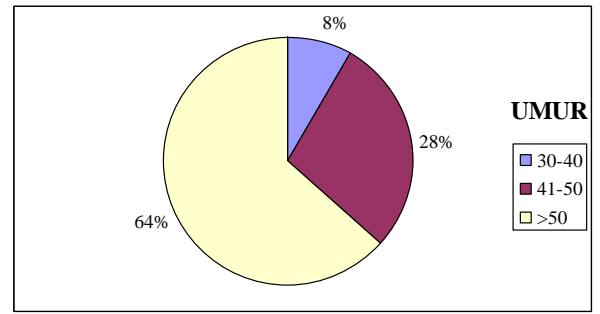

Gambar 1. Sebaran umur petani janggelan

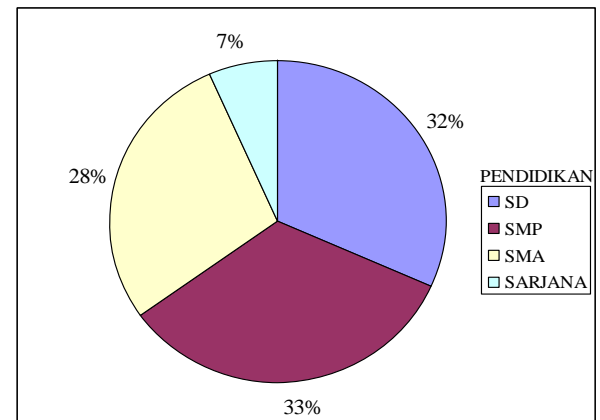

Gambar 2 . Sebaran tingkat pendidikan petani janggelan

Analisis Usaha tani Janggelan

\section{A. Biaya Total (TC) usahatani janggelan}

1. Biaya saran produksi

Besarnya biaya sarana produksi berupa pembelian pupuk urea, ponska dan pupuk kandang. Adapun biaya pembelian bibit tidak diperhitungkan karena petani menggunakan bibit dari lahan sendiri.

2. Biaya tenaga kerja

Biaya tenaga kerja dikeluarkan untuk pembiayaan upah tenaga tanam, tenaga perawatan, tenaga panen.

3. Biaya lain lain

Biaya lain lain berupa biaya untuk pembanyaran tranportasi kelahan meliputi sewa mobil dan biaya bahan bakar (Tabel 2).

Tabel 2. Biaya total

\begin{tabular}{llr}
\hline No & Keterangan & Per Hektar \\
\hline 1 & Biaya pupuk urea & 244.807 \\
2 & Biaya pupuk ponska & 300.906 \\
3 & Biaya pupuk kandang & 757.793 \\
4 & Biaya tanam & 1.137 .540 \\
5 & Biaya rawat & 896.523 \\
6 & Biaya panen & 766.540 \\
7 & Biaya transportasi & 587.478 \\
\hline & Biaya Total & 4.691 .586 \\
\hline
\end{tabular}


Website : http://agritek.unmermadiun.ac.id/index.php/agritek

\section{B. Penerimaan (TR) usahatani janggelan}

Penerimaan usahatani janggelan diperoleh dengan mengalikan produksi janggelan dengan harga janggelan (Tabel 3).

Tabel 3. Penerimaan

\begin{tabular}{llr}
\hline No & Keterangan & Jumlah \\
\hline 1 & Hasil $(\mathrm{kg})$ & $1.522,1458$ \\
2 & Harga $/ \mathrm{kg}$ & 10.000 \\
\hline & Penerimaan & 15.221 .458 \\
\hline
\end{tabular}

\section{Pendapatan Usahatani Janggelan}

Pendapatan usahatani janggelan diperoleh dari selisih antara penerimaan ( TR) dengan biaya pengeluaran (Tabel 4). Budidaya janggelan dikawasan hutan pinus layak dilakukan dengan indikator R/C sebeasr 3,24. R/C ini lebih rendah daripada budidaya janggelan di Wonogiri. R/C rasio 4,51 (Thresia, et al., 2016), namun lebih inggi dari usahatani tomat di Kelurahan Boyaoge Kecamatan Tatanga Kota Palu layak untuk diusahakan, yang ditunjukkan oleh nilai revenue cost ratio (R/C-ratio) sebesar 1,76 (Fadli, 2014) dan R/C rasio tanaman wortel di karanganyar sebesar 2,75 (Sunadari, 2011). Petani kedelai di Kecamatan Jatiwaras, Kabupaten Tasikmalaya, Provinsi Jawa Barat melakukan usahatani kedelai di lahan darat dengan nilai R/C 2,01 sedangkan nilai R/C pada lahan sawah 1,28 (Djuliansah et al., 2019)

\begin{tabular}{llr} 
Tabel 4. Pendapatan usaha tani janggelan dan R/C rasio \\
\hline No & Keterangan & Per Hektar \\
\hline 1 & Penerimaan (TR) & 15.221 .458 \\
2 & Biaya Total (TC) & 4.691 .586 \\
\hline & Pendapatan & 10.529 .872 \\
\hline & R/C & 3,24 \\
\hline
\end{tabular}

Hubungan antara faktor produksi janggelan dengan hasil janggelan dapa dikeahui dengan menggunakan analisa dengan menggunakan model Cobb-Douglas. Hasil analisa dengan metode Cobb-Douglas adalah sebagai berikut :

$$
\begin{aligned}
\operatorname{Ln} Y= & -0,741-0,024 \operatorname{Ln} X 1+1,310 \operatorname{Ln} X 2-1,048 \operatorname{Ln} X 3+ \\
& 0,642 \operatorname{Ln} X 4+0,40 \operatorname{Ln} X 5+0,130 \operatorname{Ln} X 6+0,730 \operatorname{Ln} X 7- \\
& 0,074 \operatorname{Ln} X 8-0,150 \operatorname{Ln} X 9+0,066 \operatorname{Ln} X 10
\end{aligned}
$$

Keterangan :

Ln $\mathrm{Y}=$ Produksi janggelan $(\mathrm{kg})$

Ln X1 = luas lahan $(\mathrm{m} 2)$

Ln X2 = pupuk urea $(\mathrm{kg})$

Ln X3 = pupuk ponska $(\mathrm{kg})$

Ln X4 = pupuk kandang $(\mathrm{kg})$

Ln X5 = Jarak lahan $(\mathrm{m})$

Ln X6 = jarak tanam $(m)$

Ln X7 = Biaya tanam $(\mathrm{Rp})$

Ln X8 = Biaya perawatan $(\mathrm{Rp})$

Ln X9 = Biaya panen $(\mathrm{Rp})$

Ln X10 = Biaya transportasi $(\mathrm{Rp})$

Hasil analisa ini berbeda penelitian Theresia et al (2016) yang mendapatkan bahwa produksijanggelan di KecamatanKarangtengahKabupatenWonogiri mengikuti persamaan berikut :

$$
\begin{gathered}
\operatorname{Ln} Y=7,224+0,767 \operatorname{Ln} X 1-0,162 \operatorname{Ln} X 2+0,107 \operatorname{Ln} X 3+ \\
0,001 \operatorname{Ln} X 4+0,317 \operatorname{Ln} X 5+0,007 \operatorname{Ln} X 6
\end{gathered}
$$

Keterangan :

Y : Produksijanggelan $(\mathrm{Kg})$

Ln X1 :Luaslahan yang digarap (Ha)

Ln X2 :Bibit (Batang)

Ln X3 :Pupuk urea (Kg)

Ln X4 :Pupukphonska (Kg)

Ln X5 :Pupukkandang (Kg)

Ln X6 :Tenagakerja (HKP) 
Website : http://agritek.unmermadiun.ac.id/index.php/agritek

Tabel 5. Koefesien determinasi

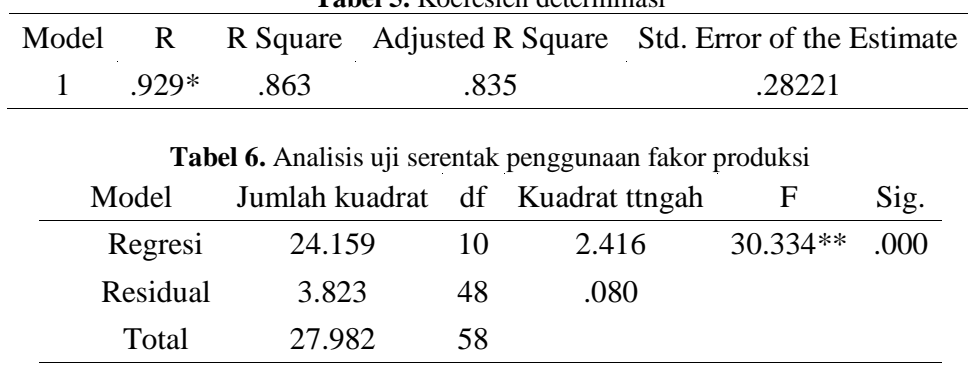

Sumbangan variabel independen terhadap variabel dependen memiliki koefesien deerminasi R2 = 0,929 (Tabel 4). Nilai Nilai R2 dalam penelitian ini lebih rendah daripada nilai R2 dari produksi janggelan di karanganyar yaitu 0,995. R2 tersebut berarti 99,5\% produksi janggelan dipengaruhi oleh factor produksi (Theresia et al., 2016)

Nilai signifikan pada tabel 6 menandakan bahwa luas lahan, pupuk urea, pupuk ponska, pupuk kandang, jarak lahan, jarak anam, biaya tanam, biaya perawatan, biaya panen, biaya angkut secara bersama sama berpengaruh terhadap produksi janggelan di kecamatan Ngrayun.

Tabel 7. Analisi uji keberartian koefesien regresi

\begin{tabular}{lrrc}
\hline & Koefesien regresi & \multicolumn{1}{c}{ t } & Sig \\
\hline (Constant) & -.741 & -.768 & .446 \\
X1(luas) & -.024 & -.390 & .698 \\
X2 (urea) & 1.310 & 2.834 & .007 \\
X3 (Ponska) & -1.048 & -2.195 & .033 \\
X4 (kandang) & .462 & 4.431 & .000 \\
X5 (Jarak lahan) & .040 & .732 & .468 \\
X6 (Jarak tanam) & .130 & .982 & .331 \\
X7 (Biaya tanam) & .370 & 2.917 & .005 \\
X8 (Biaya rawat) & -.074 & -.383 & .703 \\
X9 (Biaya panen) & -.150 & -1.061 & .294 \\
X10 (Biaya angkut) & .066 & .667 & .508 \\
\hline
\end{tabular}

Pada variabel pupuk kandang yang tertera pada tabel 7, nilai koefesiennya adalah 0,642. Hal ini menggambarkan bahwa jika pupuk kandang ditingkatkan 1 persen akan meningkatkan produksi janggelan sebanyak 0,642 persen. Demikian juga dengan biaya tanam dengan nilai koefesien sebesar 0,370, hal ini berarti produksi janggelan akan terjadi peningkaan 0,370 persen bila biaya tanam dinaikan sebesar 1 persen.

\section{IV.KESIMPULAN}

Budidaya janggelan dibawah tegakan pinus layak dilakukan $(\mathrm{B} / \mathrm{C}=3,24)$. Faktor yang mempengaruhi produksi janggelan yang paling besar adalah penggunaan pupuk kandang kemudian diikuti biaya tanam, pupuk ponska dan pupuk urea

\section{DAFTAR PUSTAKA}

Ansori T, 2018. Pemberdayaan ekonomi petani melalui KTH (kelompok tani hutan) rakyat kecamatan ngrayun kabupaten Ponorogo. Seminar Nasional Manajemen Ekonomi Akuntansi (SENMEA) 2018- UN PGRI KEDIRI :309-316.

Djuliansah D, Noor TI, Deliana Y, Rachmadi M, 2019. Kelayakan Finansial Usahatani Kedelai. Jurnal Pemikiran Masyarakat Ilmiah Berwawasan Agribisnis. 5(2): 293-303

Fadli S, 2014. Analisis pendapatan dan kelayakan usahatani tomat di kelurahan Boyaoge kecamatan Tatanga kotaPalu. J. Agroland 21 (1) : 45 - 48

Luntungan AY, 2012. Analisis tingkat pendapatan usahatani tomat apel di kecamatan tompaso Kabupaten Minahasa. Jurnal Pembangunan Ekonomi dan Keuangan Daerah (PEKD) Volume 7 No.3.

Rahayu W, Ishartani D, dan N Setyowati, 2016. Peningkatan kinerja UMKM janggelan di kabupaten Pacitan melalui introduksi teknologi produksi dan manajemen keuangan. Pengabdian masyarakat (4) 1: 45-61

Sundari MT, 2011. Analisis biaya dan pendapatan usahatani wortel di kabupaten Karanganyar.SEPA : Vol. 7 No.2: 119 - 126

Theresia J, Riptanti EW, Ani SW, 2016. Analisis penggunaan faktor-faktor produksi pada usahatani janggelan di kecamatan karang tengah kabupaten Wonogiri. Caraka Tani - Journal of Sustainable Agriculture, ( 31) 2 : 86-93

Yazid WAB, Respatijarti dan Damanhuri, 2016. Eksplorasi dan identifikasi karakter morfologi tanaman cincau hitam (mesonapalustrisbl) di Pacitan, Magetan danPonorogo. Jurnal Produksi Tanaman (4) $4: 306$ - 310

Yufit RH, Herry PB, Abdurrahman A, Dwi PT, 2017. Strategi Pengembangan Produk Unggulan Lintas Wilayah Untuk Mendukung Sistem Inovasi Daerah Di Kabupaten Magetan, Ponorogo, Dan Pacitan. Jurnal Cakrawala Vol. 11 No. 1 : 113 - 129.

Volume 21 Nomor 2 September 2020, AGRI-TEK | 67 